XVI Encontro Sobre a Cultura do Amendoim

15 a 17 de agosto de 2019 na Estação de Eventos Cora Coralina e FCAV/UNESP,

Jaboticabal-SP

\title{
ANÁLISE DO RESÍDUO SÓLIDO DO AMENDOIM NA CADEIA AGROINDUSTRIAL: UMA PESQUISA BIBLIOMÉTRICA
}

\begin{abstract}
Aline Schneiders Martins Dalpian ${ }^{1}$ e Elaine Bento de Albuquerque ${ }^{1}$
${ }^{1}$ Mestrandas em Administração - FCAVIUNESP (elaine_sbento@yahoo.com.br)

RESUMO: O trabalho tem como objetivo analisar como são realizados os procedimentos de descartes dos resíduos sólidos de impureza mineral e vegetal da cadeia produtiva do amendoim. Para tanto foi realizado uma pesquisa qualitativa em artigos selecionados onde se observou a importância da sustentabilidade como foco principal, seguindo uma série de prioridades que as agroindústrias seguem por meio do cumprimento dos requisitos normativos exigidos pela legislação, a partir do desenvolvimento de programas socioambientais em termos mais sustentáveis. O trabalho apresenta preocupações mais relevantes por parte da agroindústria quando se associa a sustentabilidade com o descarte dos resíduos sólidos provenientes do amendoim.
\end{abstract}

Palavras-Chave: Agroindústria; Amendoim; Qualidade; Sustentabilidade

\section{INTRODUÇÃO}

Os resíduos sólidos industriais são gerados nos processos produtivos e instalações industriais, de acordo com as categorias de classificação de resíduos sólidos da Política Nacional de Resíduos Sólidos - PNRS. Essa lei é regulamentada pelo Decreto n ${ }^{\circ} 7.404$ de 23 de dezembro de 2010 e apresenta diversos pontos importantes para a gestão e o gerenciamento de resíduos sólidos dentro do país, respeitando-se, prioritariamente, a seguinte ordem: não geração, redução, reutilização, reciclagem, tratamento dos resíduos sólidos e, por fim, a disposição final ambientalmente adequada (em aterros, por exemplo).

A crescente preocupação com o meio ambiente vem mobilizando vários segmentos do mercado. Inúmeros órgãos governamentais e indústrias estão se preparando para aplicar uma política ambiental que diminua os impactos negativos à natureza. Constantes revisões têm ocorrido em resoluções ligadas a resíduos, tais como a RDC 306/04, resolução da ANVISA (2004) e a Res. 388/05 do CONAMA (2007) que classificam e propõem tratamentos, forma de manipulação e descarte dos resíduos sólidos. É alto o índice de assuntos sobre Gestão Ambiental e certificação da ISO 14000, conjunto de normas que visa o desenvolvimento de atividades dos mais diversos segmentos, sem transgredir as leis ambientais vigentes.

Segundo Demajorivic (1995), resíduos sólidos diferenciam-se do termo lixo porque, enquanto este último não possui nenhum tipo de valor, já que é aquilo que deve apenas ser 


\section{Encontro Sobre a Cultura do Amendoim \\ 15 a 17 de agosto de 2019 na Estação de Eventos Cora Coralina e FCAV/UNESP, Jaboticabal-SP}

descartado, aqueles possuem valor econômico agregado, por possibilitarem reaproveitamento no próprio processo produtivo.

Em relação à indústria do amendoim afirma-se que tem crescido e ganhado destaque no mercado externo nos últimos anos. De acordo com a EMPRAPA (2018), a produção brasileira de amendoim em 2018 foi de 4.803 mil toneladas, 25,1\% a mais do que em 2017. Já a área de plantio de amendoim primeira safra, na temporada 2018/19, deverá ter incremento de 7,3\% quando comparada com a temporada anterior. A área de plantio do amendoim está estimada em 0,4 mil hectares, incremento de $16,7 \%$ em relação à safra 2017/18, produtividade de $3.785 \mathrm{~kg} / \mathrm{ha}$, redução de $0,1 \%$ em relação à safra anterior e aumento na produção de $36,4 \%$ em relação à 2017/18. Esse aumento de área se dá, principalmente, em áreas de renovação de lavouras de cana-de-açúcar.

O mercado externo absorve de $60 \%$ a $70 \%$ do total do amendoim produzido no Brasil, sendo: Rússia, Holanda e Argélia os maiores importadores. Na região da Alta Mogiana deve-se atingir 2,6 milhões de sacas de amendoim em 2019, crescimento de $10 \%$ em relação à produção de 2018.

O crescimento na produção do amendoim provoca o aumento da geração de resíduos sólidos industriais. Da colheita ao blancheamento do amendoim, são gerados resíduos sólidos de diversas naturezas. Assim, é necessário realizar pesquisas científicas com o objetivo de propor o aproveitamento dos resíduos sólidos vegetais e minerais, devido principalmente aos seus impactos no meio ambiente, nas comunidades, no rendimento financeiro do produtor e custos para as empresas beneficiadoras.

O presente trabalho apresenta como objetivo um estudo das pesquisas realizadas recentemente sobre o tema resíduo sólido de impureza mineral e vegetal gerados na indústria do amendoim. É importante a exploração do tema resíduo sólido, que compõem impureza vegetal e mineral, devido volume disposto em aterros sanitários que impactam negativamente no meio ambiente, custos para as empresas beneficiadoras do amendoim, que têm a responsabilidade de descartar o resíduo, e a perda para o produtor na entrega da produção, visto que é descontado um percentual desse resíduo antes da descarga do amendoim.

\section{MATERIAL E MÉTODOS}

O procedimento metodológico utilizado nesse estudo foi uma pesquisa exploratória de abordagem qualitativa quantitativa no formato de estudo de caso com levantamento de publicações relativas ao conhecimento sobre o tema resíduo sólido da indústria do amendoim. O tema resíduo sólido de impureza mineral e vegetal, explicitamente no caso da indústria do amendoim, faz-se importante para identificação de práticas de sustentabilidade pautados na legislação que rege as empresas relacionadas a essa atividade econômica. 


\section{Encontro Sobre a Cultura do Amendoim}

\section{5 a 17 de agosto de 2019 na Estação de Eventos Cora Coralina e FCAV/UNESP,}

Jaboticabal-SP

Foram pesquisados 240 artigos, sendo selecionados 195 de maior relevância. A pesquisa seguiu uma sequência de etapas que envolveram os critérios de seleção dos periódicos, o acesso aos artigos, análise dos artigos e apresentação dos resultados. A coleta de dados deste estudo pode ser descrita em três etapas, conforme Tabela 1.

Tabela 1:Etapas da Elaboração da Pesquisa.

\begin{tabular}{|l|l|}
\hline Etapas & Procedimentos \\
\hline Etapa 01 & $\begin{array}{l}\text { As bases de dados escolhidas para realizar as pesquisas desse estudo foram Scopus e } \\
\text { Web Of Science, devido à representatividade da academia internacional. }\end{array}$ \\
\hline Etapa 02 & $\begin{array}{l}\text { A pesquisa nas bases de dados selecionadas sobre o tema resíduo sólido impureza } \\
\text { mineral e vegetal na indústria do amendoim. Foi acessada pelo site da Capes através } \\
\text { do link de periódicos da Scopus e Web of Sciences. Estabeleceu-se realizar a pesquisa } \\
\text { dos achados no período de } 2008 \text { a 2019. }\end{array}$ \\
\hline Etapa 03 & $\begin{array}{l}\text { Foram utilizadas as palavras-chave: peanut, solidwaste, industrial waste, } \\
\text { industrial wastedisposal, impurityresidue, sustainability como critério de } \\
\text { seleção dos artigos componentes da amostra. Foram lidos os resumos de toda a } \\
\text { base de dados dos 195 estudos encontrados. }\end{array}$ \\
\hline
\end{tabular}

Fonte: Elaborado pelos Autores.

\section{RESULTADOS E DISCUSSÃO}

O foco da pesquisa realizada foi identificar práticas de descarte do resíduo sólido de impureza mineral e vegetal do amendoim, trazendo para o âmbito da cadeia da sustentabilidade uma série de pormenores apresentados em estudos de casos publicados em artigos.

De acordo com a literatura quando se trata da Gestão de Resíduo Sólido percebe-se que existe a necessidade em preocupar-se com o descarte adequado do resíduo sólido provenientes da agroindústria, devido foco em sustentabilidade e meio ambiente na sua atuação. Cumpre-se a legislação de acordo com NBR 8418/83, que trata da apresentação de Projeto de Aterros de Resíduos Industriais Perigosos e NBR 10157/87, destinando o resíduo sólido em aterros sanitários.

Ao analisar esta pesquisa foi possível identificar a existência de um grupo de pesquisadores com representatividade em estudos sobre os temas valores da organização de ser sustentável com o meio ambiente e comunidade, assim como a garantia de controle de qualidade total para assegurar que o descarte está sendo realizado de acordo com a legislação vigente. 


\section{Encontro Sobre a Cultura do Amendoim \\ 15 a 17 de agosto de 2019 na Estação de Eventos Cora Coralina e FCAV/UNESP, Jaboticabal-SP}

Em contrapartida, no contexto geral da pesquisa, houve um número baixo de artigos relacionados às agroindústrias, onde as mesmas têm como objetivo minimizar as despesas com o descarte do resíduo sólido de impureza mineral e vegetal, assim como também às análises do grau de impureza na carga de amendoim antes do descarregamento, ou seja, em alguns casos quando verificase acima de $30 \%$ o grau de impureza, a carga de amendoim é descartada, não sendo aproveitada pela empresa beneficiadora.

Houve um número razoável de artigos onde a prioridade foi demonstrar que existe orientação aos produtores quanto às boas práticas agrícolas nas regulagens de equipamentos, a fim de minimizar a geração dos resíduos.

A Tabela 2 demonstra, de forma qualitativa e por grau de importância, quais são as preocupações mais relevantes por parte da agroindústria quando se associa a sustentabilidade com o descarte dos resíduos sólidos provenientes do amendoim.

Tabela 2: Prioridade da agroindústria no descarte adequado dos resíduos sólidos de impureza vegetal e mineral de acordo com a pesquisa bibliográfica.

\begin{tabular}{|l|l|}
\hline Quantidade & Prioridades destacadas na pesquisa. \\
\hline 55 Artigos & $\begin{array}{l}\text { O cumprimento dos valores da organização de ser sustentável com o meio ambiente e } \\
\text { comunidade que está inserida. }\end{array}$ \\
\hline $\mathbf{2 5}$ Artigos & $\begin{array}{l}\text { As análises do grau de impureza na carga de amendoim são realizadas antes do } \\
\text { descarregamento e, em alguns casos, quando verifica-se acima de 30\% o grau de } \\
\text { impureza, a carga de amendoim é descartada, não sendo aproveitada pela empresa } \\
\text { beneficiadora. }\end{array}$ \\
\hline $\mathbf{4 0}$ Artigos & $\begin{array}{l}\text { As agroindústrias têm como objetivo minimizar as despesas com o descarte do resíduo } \\
\text { sólido de impureza mineral e vegetal. } \\
\text { equipamentos, a fim de minimizar a geração dos resíduos. }\end{array}$ \\
\hline 55 Artigos & $\begin{array}{l}\text { Garantia de controle de qualidade total para assegurar que o descarte está sendo } \\
\text { realizado de acordo com a legislação vigente }\end{array}$ \\
\hline
\end{tabular}

Fonte: Elaborado pelos Autores.

Quanto aos resultados apresentados, há uma grande preocupação por parte da agroindústria no que se refere à destinação deste resíduo sólido, incluindo-se aos resíduos de impureza vegetal e mineral, sendo que $70 \%$ dos estudos de casos pesquisados na literatura demonstraram que as agroindústrias trabalham para garantir que o descarte seja realizado conforme acordado com empresas contratadas para o transporte do resíduo, cumprindo a NBR 10157/87. 


\section{Encontro Sobre a Cultura do Amendoim \\ 15 a 17 de agosto de 2019 na Estação de Eventos Cora Coralina e FCAV/UNESP, Jaboticabal-SP}

\section{CONCLUSÕES}

Por meio desta abordagem bibliométrica, foi possível verificar que há a necessidade de desenvolver pesquisas com o objetivo de oferecer aproveitamento do resíduo sólido de impureza mineral e vegetal, visto que a eliminação total da sua geração está distante de ser alcançada pelos produtores, e consequentemente geram despesas para as indústrias beneficiadoras do amendoim, pois devem realizar o descarte correto em aterros sanitários para cumprir a legislação, provando impactos negativos no meio ambiente.

Sendo assim, em se tratando de sugestões em estudos científicos, para aproveitamento dos resíduos sólidos gerados na indústria do amendoim, têm-se mais pesquisas para benefício da casca, películas, e o amendoim in natura, portanto desenvolver alternativas de possível geração de renda ou diminuição de despesas para as empresas beneficiadoras com o descarte do resíduo de impureza mineral e vegetal é de grande importância.

\section{REFERÊNCIAS BIBLIOGRÁFICAS}

ANVISA - Agencia Nacional de Vigilância Sanitária. Resolução RDC n. 306. Disponível em: http://portal.anvisa.gov.br/documents/33880/2568070/res0306_07_12_2004.pdf/95eac678-d441-4033a5ab-f0276d56aaa6. Acesso em: 02 de junho de 2019.

CÂMARA, G. M. S.Introdução ao agronegócio amendoim.2014. Disponível em: http://www.lpv.esalq.usp.br/lpv506/LPV\%20506\%20A01\%20\%20Amendoim\%20Apostila\%20Agron egocio.pdf. Acesso em: 30 de maio de 2019.

CNI - Confederação Nacional das Indústrias. Meio ambiente: gerenciamento de resíduos. 2011. Disponível em http://www.portaldaindustria.com.br/cni/en/ . Acesso em: 28 de maio de 2019.

CONAMA - Conselho Nacional do Meio Ambiente. Resolução Conama n.388. Disponível em: http://www2.mma.gov.br/port/conama/legiabre.cfm?codlegi=529. Acesso em: 01de junho de 2019.

DEMAJOROVIC, J. Da política tradicional de tratamento do lixo à política de gestão de resíduos sólidos: as novas prioridades. Revista de Administração de Empresas, v.35, p. 89, São Paulo, 1995.

EMBRAPA - Empresa Brasileira de Pesquisa Agropecuária. Indicadores Agrícolas. Disponível em: https://www.embrapa.br/busca-de-publicacoes/-/publicacao/1098606/indicadores-agricolas-v-9-n-692018. Acesso em: 01 de junho de 2019.

IEA - Instituto de Economia Agrícola. Impactos econômicos de inovações agrícolas: o caso dos cultivares de amendoim no Estado de SP. Disponível em: http://www.iea.sp.gov.br/out/ TerTexto.php?codTexto=13731. Acesso em 31 de maio de 2019.

MMA - Ministério do Meio Ambiente. Política nacional de resíduos sólidos - Lei no 12.305/2010. Brasília, 2010. Disponível em: http://www.mma.gov.br/pol\%C3\%ADtica-de-res\%C3\%ADduoss\%C3\%B3lidos. Acesso em: 30 de maio de 2019. 